\title{
Video-assisted thoracoplasty in pulmonary tuberculosis: a retrospective study
}

\author{
Dmitry B. Giller ${ }^{1}$, Boris D. Giller ${ }^{1}$, Galina V. Giller ${ }^{1}$, Galina V. Scherbakova ${ }^{1}$, Vadim V. Koroev ${ }^{1}$, \\ Oleg Sh. Kesaev ${ }^{1}$, Yakub G. Imagozhev ${ }^{2}$, Aleksey A. Glotov ${ }^{1}$
}

${ }^{1}$ M.I. Perelman Department of Phthisiopulmonology and Thoracic Surgery, I.M. Sechenov First Moscow State Medical University (Sechenov University), Moscow, Russia; ${ }^{2}$ Hospital Therapy Department, Medical Faculty, FGBEI HE Ingush State University, Magas, Russia

Contributions: (I) Conception and design: DB Giller; (II) Administrative support: All authors; (III) Provision of study materials or patients: All authors; (IV) Collection and assembly of data: All authors; (V) Data analysis and interpretation: All authors; (VI) Manuscript writing: All authors; (VII) Final approval of manuscript: All authors.

Correspondence to: Dmitry B. Giller, MD, PhD. 107258, 19 Detskaya Str., Apt.74, Moscow, Russia. Email: giller-thorax@mail.ru.

Background: The long history of the struggle against tuberculosis (TB) inspired us to develop a new minimally invasive technique of thoracoplasty with videothoracoscope control (VATP). The aim of this study was to determine its efficacy.

Methods: We conducted a retrospective single-center study of a cohort of patients operated on between 1999 and 2017. Two hundred eight patients who were indicated for thoracoplasty with verified TB with cavities in the upper lobe/S6 were enrolled in this study. Treatment outcomes were assessed based on Laserson criteria and active TB absence verified with CT.

Results: Intraoperative and postoperative complications were observed in $15(7.2 \%)$ and $4(2.0 \%)$ cases, respectively. There were no 30-day mortalities. VATP with curative intent succeeded in $88 \%$ of cases according to Laserson criteria and active TB absence verified with computed tomography (CT). Clinical improvement (sputum negativity, closure of caverna, and lack of reactivation for 3 years) was achieved in $81 \%$ of cases.

Conclusions: Comparing the successful results of this technique in the cohort of multidrug-resistant (MDR) TB patients with the outcomes of treatment of MDR TB worldwide (77\% vs. 55\%, respectively), the VATP technique is shown to be efficacious and thus recommended.

Clinical trial registry number: ISRCTN67743278.

Keywords: VATS; thoracoplasty; tuberculosis (TB); multidrug-resistant (MDR); extensively drug-resistant (XDR)

Submitted Aug 21, 2019. Accepted for publication Nov 12, 2019.

doi: $10.21037 /$ jtd.2019.11.67

View this article at: http://dx.doi.org/10.21037/jtd.2019.11.67

\section{Introduction}

Tuberculosis (TB) exhibiting as drug-resistant mycobacteria tuberculosis (MTB) has become an important problem (1). In Russia, newly diagnosed TB patients are very frequently identified with extensively drug-resistant (XDR) or multidrug-resistant (MDR) TB, both of which indicate unfavorable chemotherapy outcome (2). Radical surgery cannot be offered for every patient with an ineffective chemotherapy course, but in many patients with poor prognosis and the impossibility of surgical resection, the situation can be corrected with collapse surgery techniques.

In the last part of the 20th century, curative extrapleural thoracoplasty disappeared from the thoracic surgery arsenal in the majority of countries, though it has been episodically applied in some countries with a high TB incidence. Important reasons for discontinuing thoracoplasty include its high grade of invasiveness, expressed pain effect, cosmetic and functional defects, as well as subsequent disability, which has been emphasized 
Table 1 Chemotherapy regimens (6)

\begin{tabular}{|c|c|c|}
\hline \multirow{2}{*}{ Regimen } & \multicolumn{2}{|c|}{ Chemotherapy phase } \\
\hline & Intensive & Continuation \\
\hline I & 2-3 H R Z E (S) & $\begin{array}{l}4^{\star} \mathrm{HR} / 4^{\star} \mathrm{HRE} 5^{\star \star} \\
\mathrm{HRE}\end{array}$ \\
\hline II & $\begin{array}{l}3 \mathrm{Km} / \mathrm{Am}(\mathrm{Cm}) \mathrm{R} \mathrm{Z} \mathrm{Fq}(\mathrm{E}) \\
\text { (Pto/Eto) }\end{array}$ & 6 R Z Fq (E) (Pto/Eto) \\
\hline III & 2-3 H R Z E & $4^{\star} \mathrm{HR} 5^{\star \star} \mathrm{HRE}$ \\
\hline IV & $\begin{array}{l}8 \text { Cm Lfx Z Cs/Trd PAS Pto/ } \\
\text { Eto ( Km/Am) (E) (Mfx) (Bq) }\end{array}$ & $\begin{array}{l}\text { 12-18 Lfx Z Cs/Trd PAS } \\
\text { Pto/Eto (E) (Mfx) }\end{array}$ \\
\hline V & $\begin{array}{l}8 \mathrm{Cm} \text { Mfx (Lfx) Z Cs/Trd PAS } \\
\mathrm{Bq}^{\star \star \star} \text { Lzd (E) (Pto/Eto) (Amx } \\
\text { Imp Clr Mp) }\end{array}$ & $\begin{array}{l}\text { 12-18 Mfx (Lfx) Z Cs/Trd } \\
\text { PAS (Lzd) (E) (Pto/Eto) } \\
\text { (Amx Imp Clr Mp) }\end{array}$ \\
\hline
\end{tabular}

*, in new cases of pulmonary tuberculosis; ${ }^{* *}$, in pulmonary tuberculosis for cases after interrupted treatment, relapse, or the category "other cases of repeated treatment" (except after failure); ${ }^{\star \star \star}, \mathrm{Bq}$ prescribed for 6 months. $\mathrm{H}$, isoniazid; $\mathrm{R}$, rifampicin; Rb, rifabutin; $\mathrm{Z}$, pyrazinamid; $\mathrm{E}$, ethambutol; Km, kanamycin; Am, amikacin; Pto, prothionamide; Eto, ethionamide; Cm, capreomycin; Fq, fluoroquinolones; Lfx, levofloxacin; Mfx, moxifloxacin; Cs, cycloserine; Trd, terizidone; PAS, para-aminosalicylic acid; Lzd, linezolid; Amx, amoxicillin with clavulanic acid; Imp, imipenem with cilastatin; CIr, clarithromycin; Mp, meropenem.

by many authors (3-5).

Giller et al. in 1999 developed a new, minimally invasive technique involving extrapleural thoracoplasty with videothoracoscope control, or video-assisted thoracoplasty (VATP).

The aim of this study was to test VATP efficacy assessment in the treatment of destructive pulmonary TB. We evaluated the intraoperative and postoperative complications risk, postoperative mortality, and the direct and long-term efficacy of our modified thoracoplasty in comparison with published reports from other authors using other methods.

\section{Methods}

To assess our technique efficacy, we conducted a retrospective single-center study of a cohort of patients operated on between 1999 and 2017. The criteria for inclusion were age between 16 and 70; clinically, bacteriologically, and radiologically confirmed signs of destructive pulmonary $\mathrm{TB}$, with cavities localized in the upper lobe or in the upper lobe and S6; significant pulmonary seeding, not allowing technical lung resection without the risk of foci along the resection zone; and dyspnea grades 1 to 4 (MRC dyspnea scale) and grades 0 to 2 respiratory insufficiency (the degree of severity scale). Exclusion criteria were clinical and radiological signs of caseous pneumonia; pleural empyema; dyspnea grade 5 (MRC dyspnea scale), respiratory insufficiency grade 3 (classification by the degree of severity), and/or pulmonary and cardiac insufficiency with decompensation signs; or severe comorbidities with poor prognosis.

The study group in accordance with the above mentioned criteria included 159 men (76.4\%; 95\% CI: 70.2-81.7\%) and $49(23.6 \% ; 95 \%$ CI: $18.3-29.8 \%)$ women. The mean age was 37.6 years [SD $=6.55,95 \%$ CI: $37.6 \pm 1.203$ $( \pm 3.20 \%)]$. Before surgery, XDR was established in 101 (48.6\%; 95\% CI: 41.8-55.3\%) cases, MDR 66 (31.7\%; 95\% CI: $25.8-38.3 \%)$, PolyDR in $16(7.7 \%$; $95 \%$ CI: $4.7-12.2 \%)$, and DS was in 16 (7.7\%; $95 \%$ CI: $4.7-12.2 \%)$ patients, DR was unknown in 9 (4.3\%; 95\% CI: $2.2-8.1 \%)$ cases. The disease duration ranged from 3 months to 29 years $[M=4.86 ; S D=5.48 ; 95 \%$ CI: $4.87 \pm 1.15$ $( \pm 23.68 \%)$ ], and $88.8 \%$ (95\% CI: $83.9-92.6 \%)$ exceeded one year.

The entire series of patients received pre- and postoperative chemotherapy.

The terms of preoperative chemotherapy in the group ranged from 3 months in patients operated on urgently for bleeding up to 36 months $[\mathrm{M}=19.48 ; \mathrm{SD}=8.73 ; 95 \%$ CI: $19.48 \pm 3.423( \pm 17.57 \%)]$. Postoperative chemotherapy ranged between 10 and 28 months $[M=16.21 ; S D=5.27$; 95\% CI: $16.21 \pm 1.80( \pm 11.10 \%)]$.

The regimen and duration of chemotherapy were determined by the phthisis pulmonologist in accordance with the treatment regimens of the Russian Federation (Table 1) (6). They were based on the sputum-status $\left(\mathrm{AFB}+{ }^{-}\right)$and operating material bacteriological examination, TB activity, remaining focal changes, and MTB DR.

In the postoperative period, patients with preserved drug sensitivity received treatment according to the scheme recommended as the standard I regimen (2RHZE/4RH). Patients with established MDR and with XDR MTB received anti-TB therapy according to the standard regimen of the national guidelines, which have changed over time. According to Russian recommendations (Order No. 109), until 2014, patients with MDR/XDR-TB received a common IV chemotherapy regimen [6ZEPtK/CapFq(Cs) $(\mathrm{Pas}) / 12 \mathrm{EPtFg}(\mathrm{Cs})(\mathrm{Pas})]$. Starting in 2014, a new regulation 

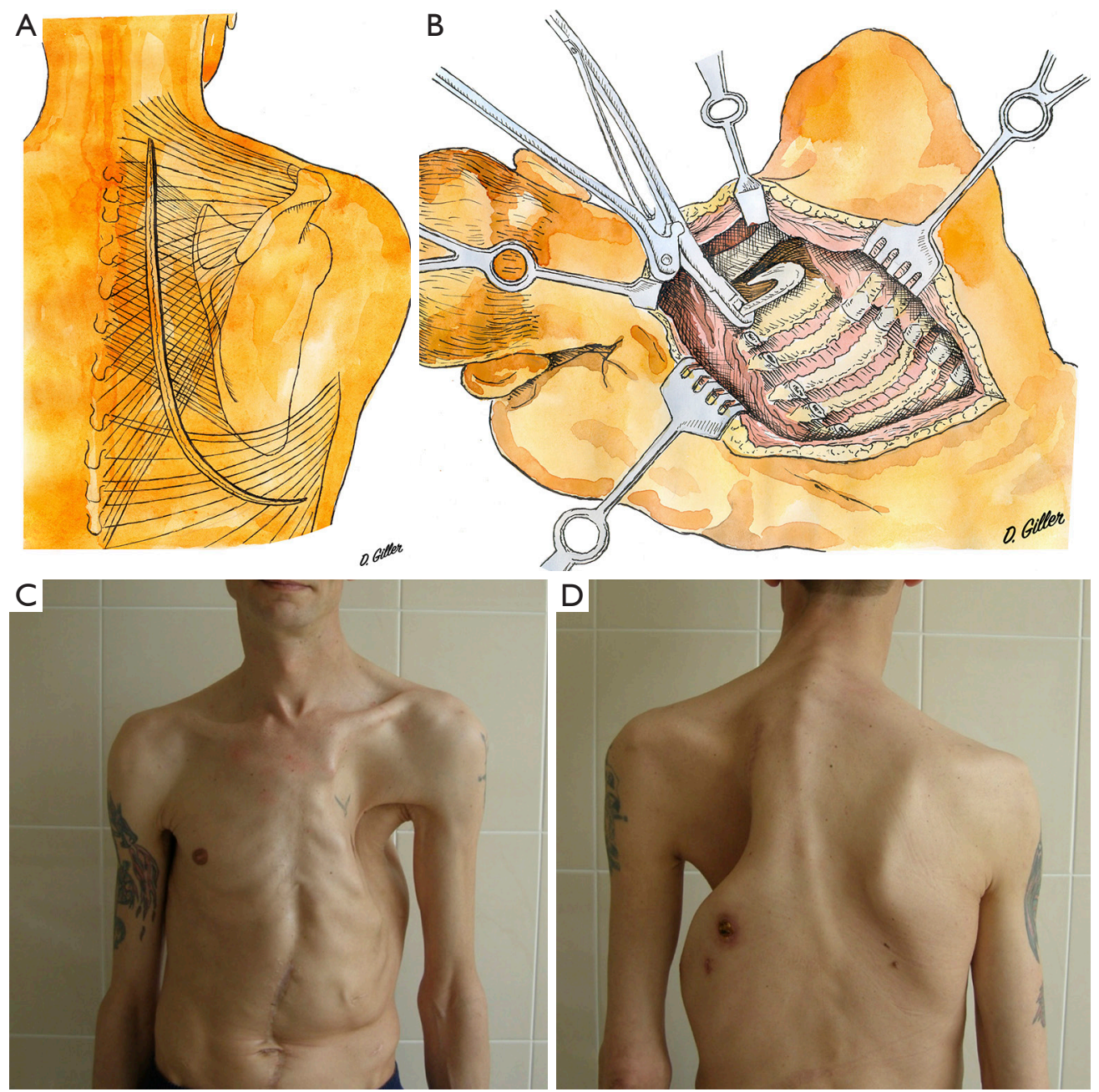

Figure 1 Conventional thoracoplasty. (A,B) J-shaped skin incision for standard extrapleural thoracoplasty; (C,D) appearance of patient after standard extrapleural thoracoplasty.

(Order of the Ministry of Health of Russia, dated December 29, 2014; No. 951) extended the chemotherapy IV regimen for patients with MDR-TB, and a new $\mathrm{V}$ treatment regimen was introduced for patients with XDR-TB (Table 1).

When MDR MTB was detected, IV chemotherapy regimen was prescribed, which included pyrazinamide and levofloxacin/moxifloxacin/sparfloxacin. But at least 5 antiTB drugs were prescribed. Postoperative chemotherapy was followed by a transition to anti-relapse courses. In the cases of XDR MTB, the V chemotherapy regimen was prescribed, which included at least six effective drugs, with priority given to moxifloxacin, bedaquilline, and linezolid. The postoperative chemotherapy in these cases was followed by a transition to preventive spring-fall therapy for 5 years.

Treatment outcomes were assessed based on two criteria:
(I) in accordance with Laserson criteria (cured: MDR/ XDR-TB patients completed treatment as planned and had at least five consecutive negative sputum cultures during the final 12 months of treatment; treatment completed: completed treatment as planned but did not meet the definition for cure due to lack of bacteriological results; failed: if two or more cultures out of the five in the final 12 months were positive, or if one out of the final three cultures were positive) (7); and (II) the absence of active TB changes verified by CT.

\section{Indications}

In the early 20th century, paravertebral thoracoplasty was usually applied for TB $(8,9)$. This requires a wide J-shaped 


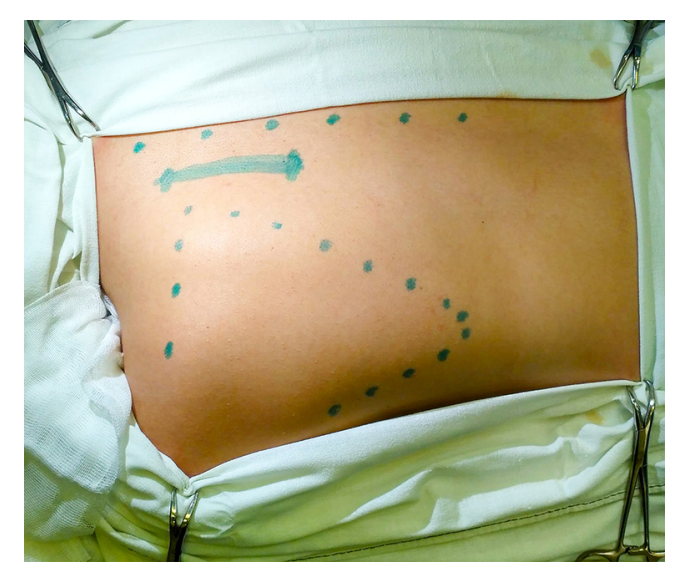

Figure 2 Section line for VATS extrapleural thoracoplasty.

skin incision (Figure 1) with sectioning of all underlying tissues up to the rib cage. This is an extremely traumatic surgery resulting in significant reduction of upper limb function, shoulder girdle muscle atrophy, and gross chest deformation in addition to the chest wall lesions. Several attempts were made to modify the surgery, such as the anterio-lateral approach (10) or rib flap forming, in which it is turned inwards after extensive pneumolysis (11). According to the data from that time, thoracoplasty indications were solitary thin-walled caverns in the upperposterior segments of the upper lobes or S6 of the lungs without focal dissemination (12-14). In modern conditions, such morpho-radiological changes serve as indications for lung resections (15).

Present indications for thoracoplasty are single/multiple cavity(ies) in the upper-posterior segments of the upper lobe and/or S6 of one or both lungs combined with massive seeding that does not allow for a lung resection to be performed (16). In addition, we often perform this technique to correct the hemithorax volume after lung resections to prevent pulmonary tissue hyperextension and $\mathrm{TB}$ reactivation. Other important data in favor of surgical treatment are MDR or XDR mycobacteria, the absence of positive dynamics despite adequate regimen, and the timing of chemotherapy and pulmonary hemorrhage. The aim of surgery is to preserve cardiorespiratory reserves.

Contraindications to curative extrapleural thoracoplasty include the presence of destructive cavities in the pulmonary parenchyma outside the zone of the alleged collapse, caseous pneumonia, severe comorbidities with signs of decompensation and poor prognosis, and low functional reserves.

\section{Technique}

The surgery technique involves an incision of $4-8 \mathrm{~cm}$ on the rib-resection side along the paravertebral line in the projection of the II-IV rib necks (Figure 2). Then, the skin, subcutaneous fat, and parts of the trapezius, rhomboid, and latissimus dorsi muscles are dissected. Together with the scapula, the dissected muscles are retracted from the external surface of the ribs in the projection following the decostation with a special hook (Figure 3). This creates a cavity between the scapula, dorsal muscles and the rib cage.

The videothoracoscope is applied to control the exposure and intersection of the anterior rib sections. It can be introduced into the cavity via the wound or a separate thoracoport $2 \mathrm{~cm}$ above the main incision. The ribs are exposed from the periosteum on the external surface with electrocautery (Figure $4 A$ ), and on the internal surface with a raspatory (Figures $3 D, G, 4 B$ ). Ribs with the transverse processes of the vertebrae are cut with rib shears (Figure $3 F$ ), posteriorly by the middle of the transverse process of the vertebra (Figure $4 C$ ), except rib I, which is cut right by the upper margin of the transverse process. Rib I is resected last. Before exposure of soft tissue, the I intercostal space is tightened with clamps downwards (Figure 4D) so that the external edge of rib I from which explosion begins is contoured.

Following preparation, first, we expose the rib I neck and cut it. Then, using a hook for the first rib (Figures $3 H, 4 E$ ), the exposed neck is pulled downwards and outwards, which makes it possible to expose the entire rib with a raspatory (Figure $4 F$ ). Then, rib I is cut in the middle part with rib shears (Figure $4 G$ ). The anterior segment is then resected with box-shaped shears (Figures 3I,4H). The first rib is cut directly by the sternum in front, and the second at the level of its transition to the cartilaginous part. All subsequent ribs, except for the lowest one, are cut off along the anterior-axillary line. The lower rib is cut off by the midaxillary line. After hemostasis control (Figure 4I), a polyvinyl chloride drain is installed via a thoracoport puncture.

Next, the extrapleural cavity plombage with hemostatic sponge plates and solutions of antibiotics in projection of the decostation is performed. The wound is sutured layer by layer. The size of the removed rib fragments far exceeds that of the access itself required for this technique (Figure 5). In the postoperative period (Figure 6), within three weeks, the formed cavity volume is increased daily with injections of antibiotic solutions and ropivacaine through the drain with regular X-ray and CT control for the collapse level of 

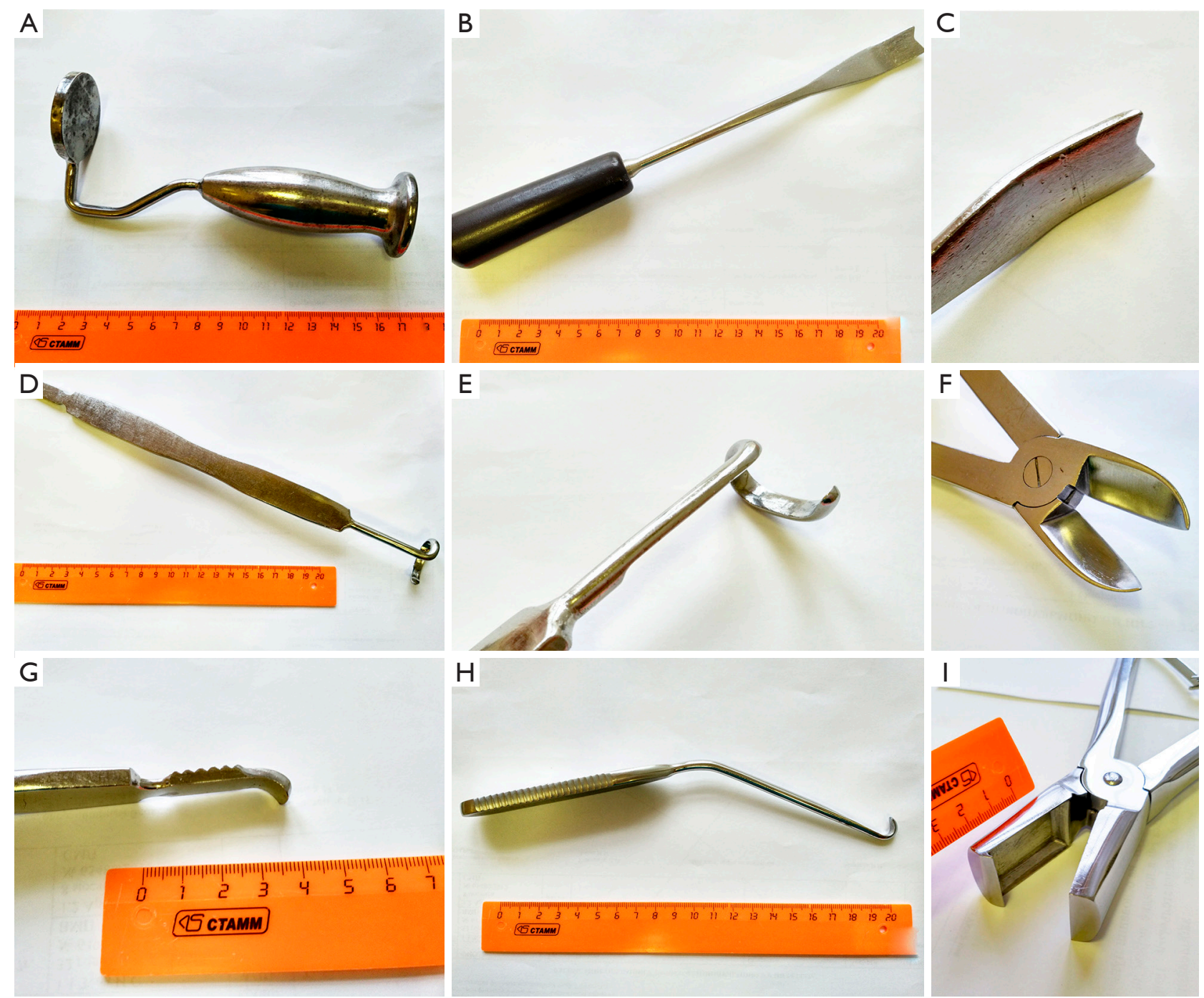

Figure 3 Thoracoplasty instrument set (from DB Giller).

pulmonary tissue and cavern.

\section{Results}

In total, 251 VATP were performed on 208 patients between 1999 and 2017 (Table 2). In 43 cases, it was bilateral. Intraoperative complications were experienced with 15 (7.2\%) patients (pleural cavity opening in 14 cases, systemic circulation vessels damage in one case). Postoperative complications (e.g., TB progression, pleurisy, pulmonary embolism, spontaneous pneumothorax, lower extremities venous thrombosis, and lung-heart failure) emerged in four $(2.0 \%)$ cases. The 30 -day mortality rate was $0 \%$, and the 90-day mortality rate was $0.5 \%$.
After applying VATP with curative intent and an adequate chemotherapy background and surgery on the opposite lung if required, we achieved an efficacy of $88 \%$ according to the WHO criteria for MTB elimination. Clinical recovery (MTB elimination, destruction cavity closure, and TB reactivation absence up to three years) was achieved in $81 \%$ of cases ( $77 \%$ with MDR, $71 \%$ XDR).

\section{Discussion}

A rather high incidence of postoperative complications (up to $46-52 \%$ ) and mortality (up to $6.7-11.7 \%$ ) follows the injury due to standard access thoracoplasty, which is now performed more often for empyema than TB $(21,22)$. 

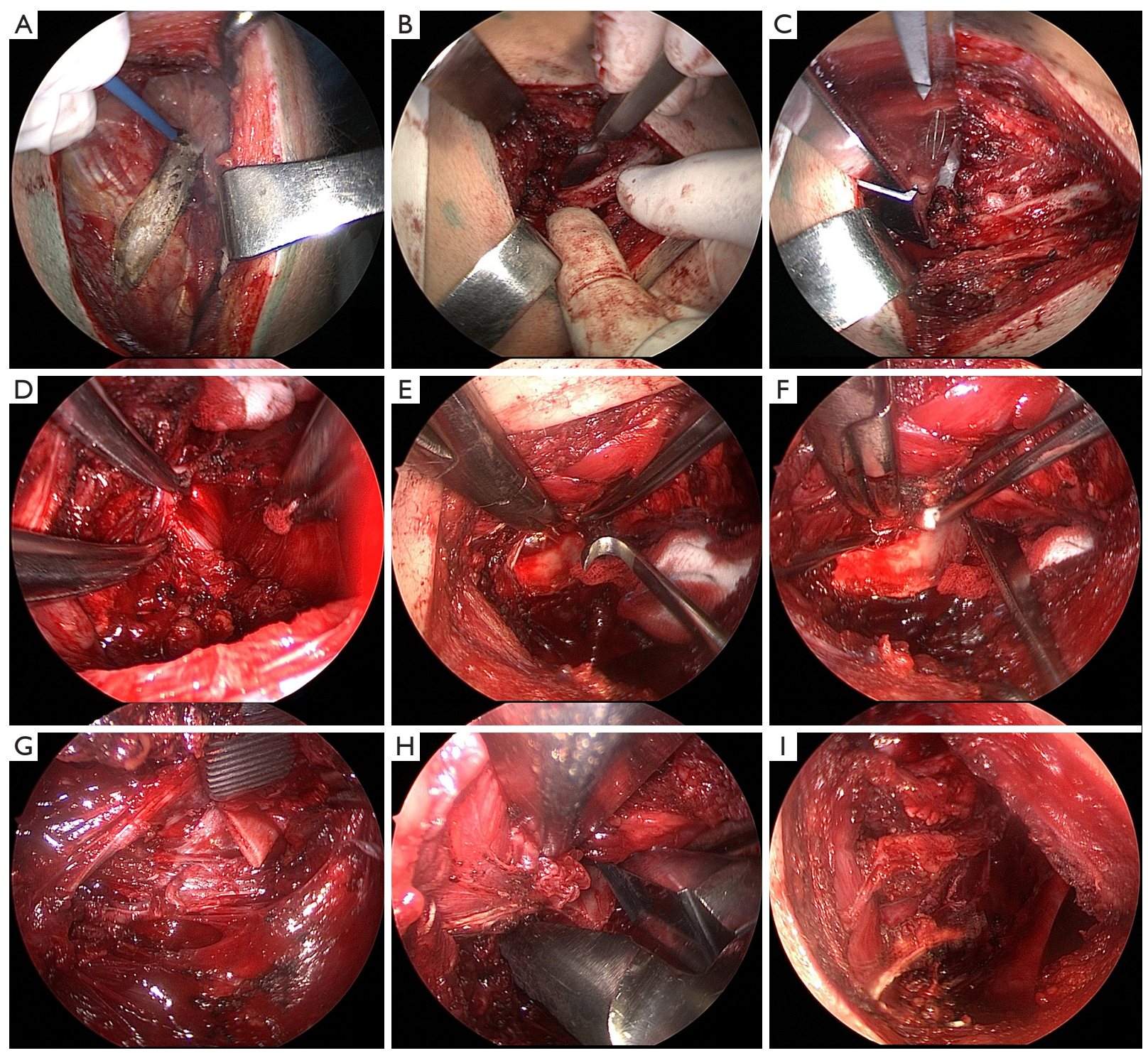

Figure 4 VATS extrapleural thoracoplasty stages.
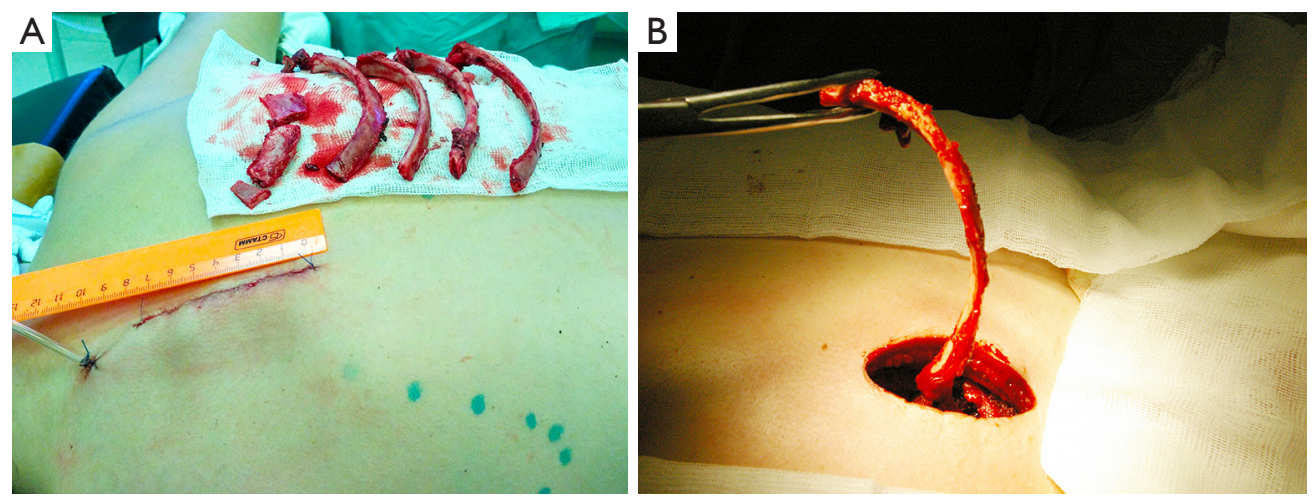

Figure 5 Decostation volume and resected rib. 

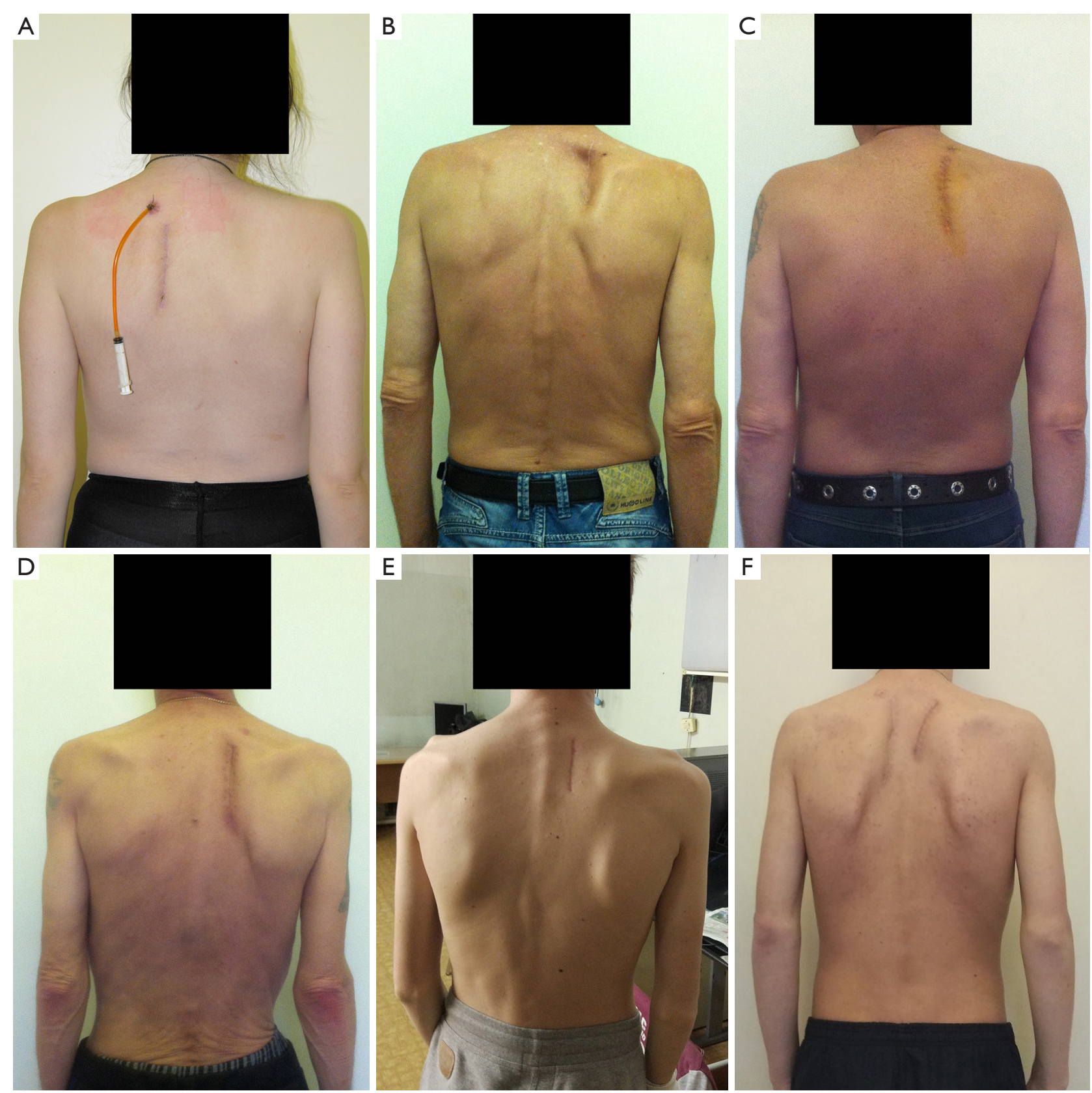

Figure 6 Appearance of patient after VATS extrapleural thoracoplasty.

In the last decade, only a few reports devoted to extrapleural therapeutic thoracoplasty have appeared in the literature. After the introduction of VATP thoracoplasty, patients have given priority to minimally invasive techniques, and combined with the retrospective study design, we were not able to provide a comparison group. Therefore, our results were compared with published data (Table 2).
The data obtained indicate a lower level of intraoperative complications with VATP, which is explained by the good visualization of tissues using the videothoracoscope. The reduction in the rate of postoperative complications and the absence of 30-day mortality in our series of surgeries may be the result of less trauma due to minimally invasive access. Extrapleural cavity sealing with long-term maintenance of the required collapse in the postoperative period made it 
Table 2 Results of extrapleural thoracoplasty in destructive pulmonary TB treatment.

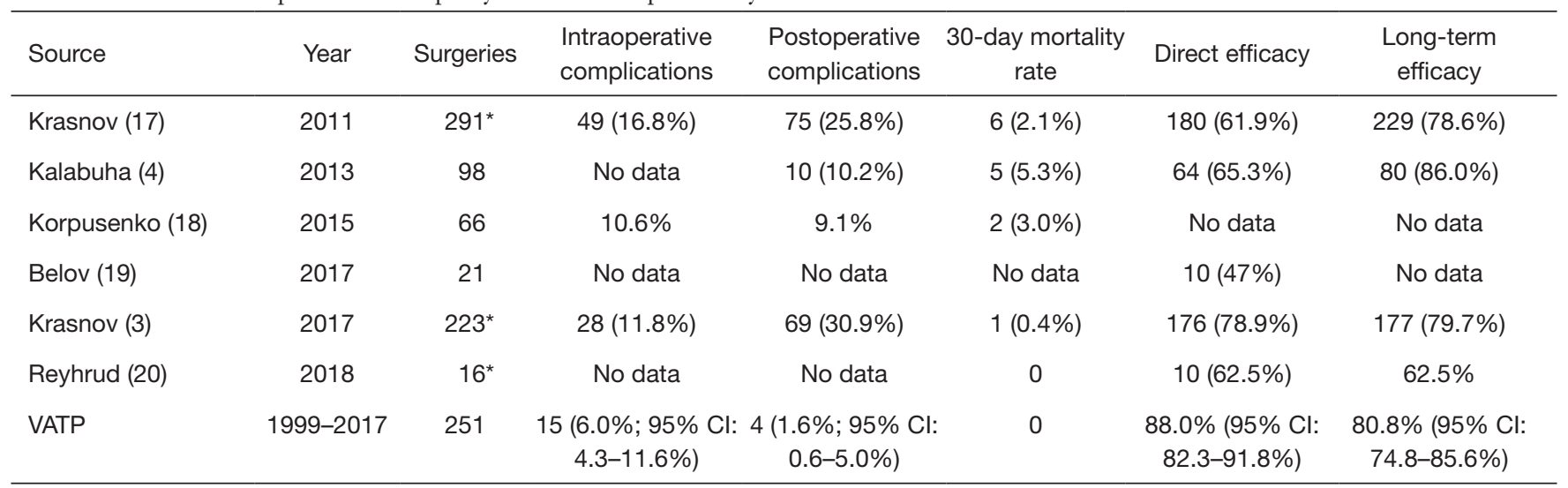

*, osteoplastic thoracoplasty + bronchoblockation. TB, tuberculosis; VATP, videothoracoscope control.

possible to achieve a relatively high direct $(88 \%)$ and longterm $(81 \%)$ efficacy.

The obvious advantage of VATP is the achievement of a high level of clinical recovery in the cohort with a high XDR/MDR rate (80.3\%), much higher than that of XDR/ MDR cases in the publications we compared our results with $(3,4,17-20)$. VATP intends complete removal of I and II ribs and therefore creates a much greater collapse than osteoplastic thoracoplasty of the Bjork type $(23,24)$ recommended by some authors $(3,20)$. At the same time, it cannot be denied that the most dangerous stage of extrapleural thoracoplasty in the classical version is the exposure of rib I in the zone of the subclavian vessels, so osteoplastic thoracoplasty may be preferable to avoid vascular damage.

The most significant weakness of our study is the lack of our own comparison group, and therefore more reliable studies should be carried out to optimize the technique of extrapleural thoracoplasty and its implementation. Given the rarity of this operation, this is feasible only in a prospective multicenter study.

The VATP technique is much less traumatic than standard extrapleural thoracoplasty $(25-27)$ due to the minimal sectioning of the dorsal muscles, vessels, and nervous branches, and it further enables a significant reduction of hemithorax volume without chest wall and shoulder girdle muscle atrophy. Patients' pain syndrome manifestation is less severe, their functional rehabilitation is full and early, chest deformation is absent, and shoulder girdle function is completely saved. Comparing the results of this technique in the cohort of MDR TB patients with the outcomes of MDR TB treatment worldwide (77\% vs. $55 \%$, respectively) (1), we regard this technique as efficacious and recommend it for use. However, it is worth noting that this technique should not be the method of choice in cases where resection is possible.

Due to the increasing prevalence of drug-resistant TB, it is possible to that extrapleural thoracoplasty should occupy a more significant place in the arsenal of thoracic surgeons, and its minimally invasive version can be qualitatively superior to crippling operations of the past.

\section{Acknowledgments}

Authors are very grateful to LetPub, for English language editing.

Funding: None.

\section{Footnote}

Conflicts of Interest: The authors have no conflicts of interest to declare.

Ethical Statement: The authors are accountable for all aspects of the work in ensuring that questions related to the accuracy or integrity of any part of the work are appropriately investigated and resolved. Ethics approval \#10-19 on 17 July 2019, Sechenov University.

Open Access Statement: This is an Open Access article distributed in accordance with the Creative Commons Attribution-NonCommercial-NoDerivs 4.0 International License (CC BY-NC-ND 4.0), which permits the noncommercial replication and distribution of the article with 
the strict proviso that no changes or edits are made and the original work is properly cited (including links to both the formal publication through the relevant DOI and the license). See: https://creativecommons.org/licenses/by-nc-nd/4.0/.

\section{References}

1. Global Tuberculosis Report 2018. World Health Organization. Available online: https://www.who.int/tb/ publications/global_report/en/

2. Tuberculosis in Russian Federation in 2012 $2013 \backslash 2014$. Analytical Review of Statistic Indicators Applied in Russian Federation and in the World. Moscow, 2015:312-8.

3. Krasnov D, Krasnov V, Skvortsov D, et al. Thoracoplasty for Tuberculosis in the Twenty-first Century. Thorac Surg Clin 2017;27:99-111.

4. Kalabuha IA, Savenkov YF, Stashenko OD, et al. Modern Collapse Surgery and Collapse Therapy for Pulmonary Tuberculosis. Dnipro-VAL 2013 - Dnipropetrovsk: 133.

5. Giller GV. Efficiency of extrapleural thoracoplasty in pulmonary tuberculosis. Probl Tuberk 2002;(11):32-3.

6. Federal clinical recommendations in pulmonary tuberculosis diagnosis and treatment. Available online: http://roftb.ru/netcat_files/doks/protokol1.pdf

7. Laserson KF, Thorpe LE, Leimane V, et al. Speaking the same language: treatment outcome definitions for multidrug-resistant tuberculosis. Int J Tuberc Lung Dis 2005;9:640-5.

8. Alexander J. NEW THORACOPLASTIC PROCEDURE FOR PULMONARY TUBERCULOSIS TO LESSEN INCIDENCE OF POST-OPERATIVE PNEUMONIA. Ann Surg 1925;81:748-56.

9. Sauerbruch F, Schumacher ED. Technik der Thoraxchirurgie. Berlin J Springer 1911.

10. Thevarthundil J. XXXX. Tubercle 1936;17:IN5-6.

11. Sellors TH, Jackson JW, Callanan JG. "Modified" thoracoplasty. Thorax 1955;10:191-6.

12. Saugman C. Thoracoplasty in the treatment of pulmonary tuberculosis. Tubercle 1920;1:305-16.

13. Drew DM, O'Rourke J. The future of thoracoplasty in pulmonary tuberculosis. Br J Tuberc Dis Chest 1958;52:319-24.

14. Shaw KM. Evolution in the surgery of pulmonary tuberculosis. J Ir Med Assoc 1958;42:92-3.

15. Giller DB, Giller BD, Giller GV, et al. Treatment of pulmonary tuberculosis: past and present. Eur J
Cardiothorac Surg 2018;53:967-72.

16. Krassas A, Grima R, Bagan P, et al. Current indications and results for thoracoplasty and intrathoracic muscle transposition, Eur J Cardiothorac Surg 2010;37:1215-20.

17. Krasnov DV, Grishenko NG, Beschetnyi TG, et al. Osteoplastic thoracoplasty with application of the endobronchial valve in complex treatment of patients with previous fibrotic-cavitary pulmonary tuberculosis. Acta biomedica scientifica 2011;2:52-7.

18. Korpusenko IV. Application of minimally invasive extrapleural thoracoplasty in patients with bilateral pulmonary tuberculosis. Novosti kjirurgii 2015;23:37-43.

19. Belov SA. Thoracoplasty with application of a polypropylene net in the treatment of lung tuberculosis. Tuberkulëz i bolezni lëgkikh 2017;95:6-9.

20. Reyhrud MV, Krasnov DV, Avdienko KA, et al. Longterm results of resection and collapsurgical interventions in pulmonary tuberculosis. Tuberkulëz i bolezni lëgkikh 2018;96:34-9.

21. Botianu PV, Botianu AM. Muscle Flaps and Thoracomyoplasty: Alternative Solution for Unresectable Primary Pulmonary Abscesses. Thorac Cardiovasc Surg 2013;61:626-30.

22. Fournier I, Krueger T, Wang Y, et al. Tailored Thoracomyoplasty as a Valid Treatment Option for Chronic Postlobectomy Empyema. Ann Thorac Surg 2012;94:387-93.

23. Bjork VO. Thoracoplasty: a new osteoplastic technique. J Thorac Surg 1954;28:194.

24. Hopkins RA, Ungerleider RM, Staub EW, et al. The modern Use of thoracoplasty. Ann Thorac Surg 1985;40:181-7.

25. Dewan R. Thoracoplasty: By no means an obsolete procedure. Indian J Thorac Cardiovasc Surg 1995;11:33-7.

26. Stefani A, Jouni R, Alifano $M$ et al. Thoracoplasty in the current practice of thoracic surgery: A single-institution 10-year experience. Ann Thorac Surg 2011;91:263-8.

27. Kuhtin O, Veith M, Alghanem M, et al. ThoracoplastyCurrent View on Indication and Technique. Thorac Cardiovasc Surg 2018. [Epub ahead of print].

Cite this article as: Giller DB, Giller BD, Giller GV, Scherbakova GV, Koroev VV, Kesaev OS, Imagozhev YG, Glotov AA. Video-assisted thoracoplasty in pulmonary tuberculosis: a retrospective study. J Thorac Dis 2020;12(3):980988. doi: 10.21037/jtd.2019.11.67 